\title{
Dexmedetomidine ameliorates gut lactate production and impairment of exogenous lactate clearance in an endotoxic sheep model
}

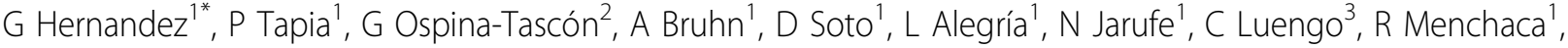 \\ A Meissner $^{1}$, MI Vives ${ }^{1}$, J Bakker ${ }^{4}$
}

From ESICM LIVES 2015

Berlin, Germany. 3-7 October 2015

\section{Introduction}

The mechanisms of persistent hyperlactemia during endotoxic shock are probably multifactorial. Both hypoperfusion-related anaerobic production and adrenergic-driven aerobic generation have been implicated. More recently an early and severe impairment in exogenous lactate clearance has also been described [1]. Theoretically, an excessive adrenergic response could influence all these mechanisms and thus aggravate the problem.

\section{Objectives}

To assess the effects of dexmedetomidine (DEX) on lactate production and exogenous lactate clearance in an endotoxic shock model.

\section{Methods}

Twelve anesthetized sheep were subjected to a multimodal hemodynamic/perfusion assessment including hepatic and portal vein catheterizations, total hepatic blood flow, sublingual microcirculation, and muscle microdialysis. After the monitoring phase, all received a $5 \mathrm{mcg} / \mathrm{kg}$ LPS bolus $\left(\mathrm{E}\right.$ coli O127:B8 ${ }^{\circledR}$ ) and then $4 \mathrm{mcg} \cdot \mathrm{kg}^{1} \cdot \mathrm{hr}^{1}$ for the rest of the experiment. After $1 \mathrm{hr}$ they were volume resuscitated, and then randomized to placebo or DEX. Sampling and exogenous lactate clearances [2] were performed at 4 points (figure 1 ).

\section{Results}

DEX was not associated with any adverse hemodynamic effect in terms of cardiac output, heart rate, mixed venous oxygen saturation, central venous-arterial $\mathrm{pCO}_{2}$ gradient

1Pontificia Universidad Catolica de Chile, Santiago, Chile

Full list of author information is available at the end of the article

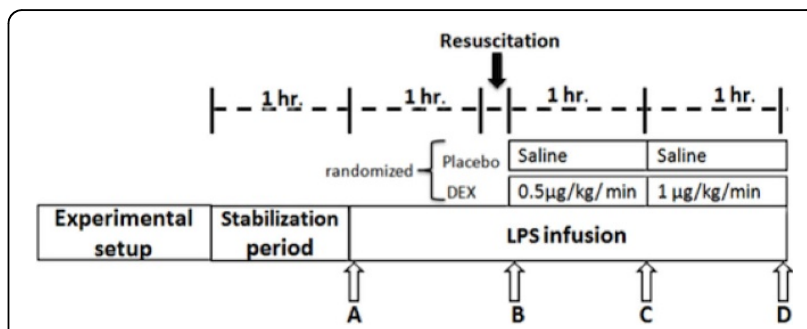

Figure 1

and NE requirements as compared to placebo. DEX animals presented significant lower epinephrine levels (4.6 \pm 1.3 vs $7.1 \pm 1.4 \mathrm{ng} / \mathrm{ml})$, arterial lactate levels $(6.4 \pm 3.1 \mathrm{vs}$ $9.2 \pm 1.8 \mathrm{mmol} / \mathrm{l})$, portal vein lactate levels $(6.2 \pm 2.2 \mathrm{vs} 8.1$ $\pm 2.0 \mathrm{mmol} / \mathrm{l})$; and higher portal vein $\mathrm{O} 2$ saturations (78 \pm 16 vs $68 \pm 11 \%)$, and exogenous lactate clearance (7.2 \pm 5.4 vs $2.9 \pm 1.5 \mathrm{ml} / \mathrm{kg} / \mathrm{min}$ ) as compared to placebo at point $\mathrm{D}$. No differences in muscle lactate production or sublingual microcirculatory parameters could be observed.

\section{Conclusions}

Dexmedetomidine ameliorates the increase in gut lactate production and impairment of exogenous lactate clearance in experimental endotoxic shock. This effect is associated with a significant reduction in systemic epinephrine levels.

\section{Grant Acknowledgment \\ FONDECYT 1130200, Chile}

\section{Authors' details}

'Pontificia Universidad Catolica de Chile, Santiago, Chile. ${ }^{2}$ Fundación Valle del Lili, Cali, Colombia. ${ }^{3}$ Universidad de Chile, Santiago, Chile. ${ }^{4}$ Erasmus MC University Medical Center, Rotterdam, the Netherlands. (c) 2015 Hernandez et al.; This is an Open Access article distributed under the terms of the Creative Commons Attribution License (http://creativecommons.org/licenses/by/4.0), which permits unrestricted use, distribution, and reproduction in any medium, provided the original work is properly cited. 


\section{References}

1. Tapia P, Soto D, Bruhn A, Regueira T, Jarufe N, Alegria L, et al: 0101. Early and severe impairment of lactate clearance in endotoxic shock is not related to liver hypoperfusion: preliminary report. Intensive Care Medicine Experimental 2014, 2(Suppl 1):P12.

2. Levraut J, Ciebiera JP, Chave S, Rabary O, Jambou P, Carles M, Grimaud D: Mild hyperlactatemia in stable septic patients is due to impaired lactate clearance rather than overproduction. Am J Respir Crit Care Med 1998, 157:1021-1026.

doi:10.1186/2197-425X-3-S1-A414

Cite this article as: Hernandez et al: Dexmedetomidine ameliorates gut lactate production and impairment of exogenous lactate clearance in an endotoxic sheep model. Intensive Care Medicine Experimental 2015 3(Suppl 1):A414.

\section{Submit your manuscript to a SpringerOpen ${ }^{\mathcal{O}}$ journal and benefit from:}

- Convenient online submission

- Rigorous peer review

- Immediate publication on acceptance

- Open access: articles freely available online

- High visibility within the field

- Retaining the copyright to your article 